\title{
Proceeding
}

Performance Analysis Workshop, 2 - 5 April 2013, Alicante, Spain

\section{Biomechanical analysis of the final strides of the approach and the take-off by visually impaired class F12 and F13 long jumpers}

\author{
VASSILIOS PANOUTSAKOPOULOS1, APOSTOLOS THEODOROU1 1, , MARIANA C. \\ KOTZAMANIDOU3 ${ }^{3}$ EMMANOUIL SKORDILIS², IRAKLIS A. KOLLIAS ${ }^{1}$ \\ ${ }^{1}$ Biomechanics Laboratory, Department of Physical Education \& Sports Science, Aristotle University of Thessaloniki, \\ Thessaloniki, Greece \\ ${ }^{2}$ Department of Physical Education \& Sports Science, Kapodistrian University of Athens, Athens, Greece \\ ${ }^{3}$ Faculty of Health and Human Sciences, Akmi Metropolitan College Thessaloniki, Thessaloniki, Greece
}

\begin{abstract}
Panoutsakopoulos V, Theodorou A, Kotzamanidou MC, Skordilis E, Kollias IA. Biomechanical analysis of the final strides of the approach and the take-off by visually impaired class F12 and F13 long jumpers. J. Hum. Sport Exerc. Vol. 8, No. Proc3, pp. S671-S680, 2013. Despite of the level of visual aquity, European Records in long jumping are greater in class F12 (visual acuity 2/60) than class F13 (visual acuity 6/60) both in males and females. The aim of the present study was to compare the biomechanical parameters of the final strides of the approach and the take-off in class F12 and F13 long jumpers. 19 class F12 (males: 13, females: 6) and 12 class F13 (males: 4, females: 8) long jumpers participating in the 2009 International Blind Sports Association European Championships were recorded using a stationary digital video camera (sampling frequency: $300 \mathrm{fps}$ ). Key biomechanical parameters were extracted with a typical 2D-DLT kinematical analysis. Differences between groups were investigated using Independent samples t-test. Results indicated that the official distance was $6.07 \mathrm{~m} \pm 0.55$ and $5.52 \mathrm{~m} \pm 0.91$ for $\mathrm{F} 12$ and F13 respectively $(\mathrm{p}<.05)$. Significant differences were also observed concerning the vertical take-off velocity (F12: $2.8 \mathrm{~m} / \mathrm{sec}, \mathrm{F} 13: 2.4 \mathrm{~m} / \mathrm{sec}$ ), the support leg's knee flexion (F12: $18.2 \mathrm{deg}, \mathrm{F} 13: 25.2 \mathrm{deg}$ ) and the knee joint flexion velocity (F12: $7.4 \mathrm{rad} / \mathrm{sec}, \mathrm{F} 13: 10.2 \mathrm{rad} / \mathrm{sec}$ ) at the take-off board and the knee maximum flexion angle at the last stride (F12: 116.8 deg, F13: 125.4 deg). In conclusion, F12 performed better than F13 because of the more advantageus utilization of the factors defining the vertical component in the longjump take-off. Additionally, the different last stride maximum knee flexion angle might imply differences concerning the mechanics of the placement of the take-off leg. It is possible that factors such as the size and surface properties of the $1.22 \mathrm{~m} \times 1.00 \mathrm{~m}$ chalked take-off area used in F12 competition may contribute to the differences observed in the study. Key words: 2D-DLT ANALYSIS, STRIDE LENGTH, JOINT ANGULAR KINEMATICS, VISUAL ACUITY, TECHNIQUE
\end{abstract}

Corresponding author. Department of Physical Education and Sport Science. Kapodistrian University of Athens 41 Ethnikis E-mail: aptheod@phed.uoa.gr

Performance Analysis Workshop, 2 - 5 April 2013, Alicante, Spain

JOURNAL OF HUMAN SPORT \& EXERCISE ISSN 1988-5202

(c) Faculty of Education. University of Alicante

doi:10.4100/jhse.2013.8.Proc3.13

VOLUME 8 | Proc3 | 2013 | S671 


\section{INTRODUCTION}

Long jump consists an event of the Paralympic Games. From 1976 onwards, visually impaired jumpers are elegible to compete under three distinct classes, i.e. F11 (no vision), F12 (visual acuity: 2/60) and F13 (visual acuity: 6/60). Nevertheless, despite of the reduced visual aquity, European Records in long jumping in class F12 are greater by $2 \%$ in males and $12 \%$ in females compared to class F13.

Besides the dominating factor of approach velocity, another important determinant of performance in long jumping is the accuracy of foot planting on the take-off board (Hay, 1986). Long jumpers, in order to minimize their toe-to board distance (Sттв), regulate their stride length approximately at the final 4 or 5 strides of the approach (Berg \& Greer, 1995; Bradshaw \& Aisbett, 2006; Galloway \& Connor, 1999; Glize \& Laurent, 1997; Hay, 1988; Hay \& Koh, 1988; Lee et al., 1982; Scott et al., 1997). In order to conduct the desired regulation, the majority of long jumpers seek to acquire the necessary visual information by directing their gaze towards the take-off board during the final three strides of the approach (Berg et al., 1993). The regulation observed of the final strides consists in the adjustment of the body segment configuration in order jumpers to prepare for the take off. The technical execution of the last strides prior to take-off found to be a significant factor concerning the official distance (SOFF) that an athlete can achieve (Hay, 1993; Hay \& Miller, 1985; Hay et al., 1986; Hay \& Nohara, 1990; Panoutsakopoulos et al., 2010; Shimizu et al., 2011; Shimizou et al., 2012). This is being accomplished mainly by elongating the penultimate stride length compared to the previous strides, a technique element characterized as "larger penultimate - shorter last stride" (Hay \& Miller, 1985). The adoption of the above technique in the final part of the approach causes the body center of mass (BCM) to lower in the penultimate stride (Hay \& Nohara, 1990). This action creates favourable conditions for developing higher vertical take-off BCM velocity without demanding an extensive reduction of horizontal BCM velocity during the push-off at the take-off board (Bruggemann \& Conrad, 1986). Additionally, this technique contributes to the larger BCM vertical displacement at the same time (Ridka-Drdacka, 1986).

Research conducted on visually impaired long jumpers revealed that these athletes adopt a similar regulation pattern up to the final 4-5 strides of the approach (Theodorou \& Skordilis, 2012; Theodorou et al., 2011; Theodorou et al., 2012a). Nevertheless, the greater amount of stride length adjustment caused by visual regulation has found to be conducted in the final two strides of the approach (Hay, 1988; Montagne et al., 2000). As mentioned above, in this final part of the approach is crucial for Soff, since the determining prerequisites for maximizing the take-off parameters are being developed (Hay \& Nohara, 1990). However, no relevant study was found in the literature addressing the issue of how visually impaired long jumpers adjust their technique in order to prepare for the take-off.

Based on the above, the purpose of the study was to examine the possible technique modifications of visually impaired long jumpers when executing the last strides and the take-off, taking under consideration that they experience the acquisition of limited visual information during the approach. Furthermore, the comparison of the biomechanical parameters of the final strides of the approach and the take-off in class F12 and F13 long jumpers could provide additional information concerning the contradicting phenomena of F12 achieving larger jumping distances despite their lesser visual acuity. 


\section{MATERIAL AND METHOD}

\section{Participants:}

19 class F12 (13 males and 6 females; 25.9 years $\pm 6.4,1.71 \mathrm{~m} \pm 0.04,73.7 \mathrm{~kg} \pm 5.5$ ) and 12 class F13 (4 males and 8 females; 24.8 years $\pm 6.4,1.74 \mathrm{~m} \pm 0.05,74.5 \mathrm{~kg} \pm 4.7)$ long jumpers were recorded during their participation in the 2009 International Blind Sports Association European Championships (Rhodes, Greece: 4-14.6.2009). The participants were included in the study because of their official classification as F12 and F13 class athletes by the IBSA and the IPC medical boards, and the confidence that the respective athletes comprised a group representative of top European visually impaired long jumpers. The research was conducted after the provision of permission by IBSA and in accordance to the University's Research Ethics Code for the use of human subjects.

\section{Instrumentation \& Procedures:}

All the attempts of the participants were recorded using a stationary Casio EX-F1 (Casio Computer Co. Ltd, Shibuya, Japan) digital video camera set to a sampling frequency of 300 frames per second. The camera was fixed on a rigid tripod which was placed at a height of $1.2 \mathrm{~m}$ and at a distance of $3.7 \mathrm{~m}$ before the takeoff line and $14 \mathrm{~m}$ from the middle of the run-way. The camera was placed perpendicular to the plane of motion and recorded the right-sided view of the last three strides of the approach ( $3 \mathrm{~L}, 2 \mathrm{~L}$, and $1 \mathrm{~L})$ and the take-off from the board (BO). The calibration of the recorded view was accomplished by consecutively placing a $0.02 \mathrm{~m} \times 2.0 \mathrm{~m}$ pole in several predefined spots within the filming view in order to produce twodimensional coordinates with the use of a 2D-DLT kinematical analysis method (Kollias, 1997). The X-axis represented the direction of the runway and $Y$-axis was vertical and perpendicular to the $X$-axis.

All trials were recorded but the best valid jump for each athlete was selected for further analysis. The video files were processed with the Adobe Premiere 5.1 software (Adobe Systems Incorporated, San Jose, CA) in order to extract the video-fields. Twenty-two anatomical points of the body (tip of the toe, 5th metatarsal, heel, ankle, knee, hip, shoulder, elbow, wrist and 5th metacarpal on both sides of the body, 7th cervical vertebra and the top of the head) were manually digitized in each field using a custom made twodimensional analysis software (Clraklis A. Kollias). The coordinates of the BCM were calculated for every field using the anatomical data provided from Dempster (1955). A 2nd order low-pass Butterworth filter with a cut-off frequency ranging from 6.2 to $11.2 \mathrm{~Hz}$, based on the noise calculated with residual analysis (Winter, 1990), was selected for smoothing. The accuracy of the 2D reconstruction was determined by Root Mean Square error, after randomly re-digitizing $1 \%$ of the captured frames. An error of $0.4 \mathrm{~cm}$ and $0.7 \mathrm{~cm}$ was found for the $\mathrm{X}$ - and $\mathrm{Y}$-axis, respectively.

\section{Measures:}

The time instant of touchdown was defined at the first field where the foot had clearly contacted the ground. The time instant of take-off was defined at the first field where the foot had clearly left the ground. Thus, contact ( $\mathrm{tc}_{\mathrm{c}}$ ) and flight ( $\mathrm{t}_{\mathrm{FL}}$ ) time could be extracted for each stride. The braking phase of the take-off was defined as the period from touchdown to the board to the maximum flexion of the support leg's knee joint, while from that instant to the take-off was assumed as the propulsive phase (Lees et al., 1993).

Furthermore, the following biomechanical parameters were calculated based on the $X Y$ coordinates extracted for the digitized anatomical points:

- Stride frequency (SF): the number of strides taken per second.

- Stride length $(S)$ : the horizontal distance between the touchdown points of the feet recorded for two consecutive supports. 
- Touchdown distance (SтD): the horizontal distance of the toes of the support foot to BCM projection at the instant of touchdown.

- Take-off distance $\left(\mathrm{S}_{\mathrm{T} O}\right)$ : the horizontal distance of the toes of the support foot to the BCM projection at the instant of take-off.

- Horizontal $\mathrm{BCM}$ velocity $(\mathrm{Vx})$ : the first-time derivative of the horizontal $\mathrm{BCM}$ displacement.

- Vertical BCM velocity (Vy): the first-time derivative of the vertical BCM displacement.

- Angle of take-off (AngPr): the arc-tangent of the ratio of the vertical to the horizontal BCM velocity at the instant of take-off.

- Horizontal ankle touchdown velocity $\left(V_{A} T D\right)$ : the horizontal velocity of the ankle at the instant of touchdown.

- BCM height $\left(\mathrm{H}_{B C M}\right)$ : the height of the BCM at the instants of touchdown $\left(\mathrm{H}_{\mathrm{TD}}\right)$, of its maximum lowering during the support phase $\left(\mathrm{H}_{\mathrm{Am}}\right)$ and toe-off $\left(\mathrm{H}_{T O}\right)$.

- Support leg knee joint angle: the angle formed between the thigh and the shank at the instants of touchdown $\left(\theta \mathrm{k}_{\mathrm{T} D}\right)$, of its maximum flexion ( $\theta \mathrm{k}_{\mathrm{MF}}$ ) and take-off $\left(\theta \mathrm{k}_{\mathrm{TO}}\right)$. The magnitude of the joint's flexion $\left(\theta \mathrm{k}_{\mathrm{FLEX}}\right)$ and extension $\left(\theta \mathrm{k}_{\mathrm{EXT}}\right)$ during the support phases was also calculated.

- Swing leg knee joint angle: the angle formed between the thigh and the shank at the instants of take-off $(\theta \mathrm{ksw})$.

- Knee joint angular velocity: the maximum value of the angular velocity of the support leg's knee joint during the support, where positive values expressing the extension ( $\omega \mathrm{K}_{\mathrm{EXT}}$ ) and negative values the flexion of the joint ( $\omega \mathrm{K}_{\mathrm{FLEX}}$ ).

- Thigh inclination $(\varphi т н)$ : angle formed by the horizontal axis and the thigh of the swing leg at the instant of take-off.

- Torso inclination: the angle between the horizontal level and the line connecting the midpoints of the hips and shoulder joints' axis at the instant of touchdown ( $\varphi$ TRSTD) and take-off ( $\varphi$ TRSTO). Mechanical Work: the mechanical work done at the braking (WBR) and the propulsive (WPR) phase expressed per kg of body mass computed as proposed by Lees et al. (1993).

Statistical Analysis:

Data are expressed as mean \pm standard deviation. The two groups were checked for normal distribution (Kolmogorof-Smirnof test, $p>0.05$ ) and equality of variance (Levene's test, $p>0.05$ ). Differences concerning the biomechanical parameters were examined with an Independent Samples t-test using the SPSS 10.0.1 software (SPSS Inc., Chicago, II) set to a level of significance was set at $p=0.05$.

\section{RESULTS}

SOFF was significantly $\left(t_{1,29}=2.109, p<.05\right)$ different between the examined groups $(6.07 \mathrm{~m} \pm 0.55$ and $5.52 \mathrm{~m} \pm 0.91$ for $\mathrm{F} 12$ and F13, respectively). The outcome of the comparizon between groups concerning the approach parameters is presented in Table 1. No statistical significant differences were observed concerning Vx, SF and S, although the detection of a tendency $(p=.07)$ that $F 12$ had a larger maximum Vx value for the last three strides of the approach. The only significant difference $\left(t_{1,29}=2.109, p<.05\right)$ revealed for the approach was $S_{\text {TD }}$ of $1 \mathrm{~L}(-0.47 \mathrm{~m} \pm 0.08$ and $-0.39 \mathrm{~m} \pm 0.08$ for F12 and F13, respectively). 
Table 1. Comparison of the biomechanical parameters of the approach between the examined class F12 and F13 long jumpers (see text for the abbreviations used)

\begin{tabular}{|c|c|c|c|c|c|c|c|c|}
\hline oarar & F12 & & & F13 & & & $t$ & $p$ \\
\hline S3L (m) & 1.95 & \pm & 0.16 & 1.89 & \pm & 0.15 & 1.015 & .318 \\
\hline S2L (m) & 2.12 & \pm & 0.22 & 2.00 & \pm & 0.17 & 1.688 & .102 \\
\hline & 1.88 & \pm & 0.09 & 1.82 & \pm & 0.21 & 0.892 & .388 \\
\hline & 4.72 & \pm & 0.34 & 4.81 & \pm & 0.49 & 0.635 & .531 \\
\hline & 4.18 & \pm & 0.44 & 4.07 & \pm & 0.41 & 0.727 & .474 \\
\hline & .23 & \pm & 0.30 & 4.17 & \pm & 0.31 & 0.601 & .553 \\
\hline Vx3l & 3.45 & \pm & 0.50 & 8.15 & \pm & 0.62 & 1.268 & .215 \\
\hline Vx2L (1 & 8.82 & \pm & 0.60 & 8.37 & \pm & 0.90 & 1.695 & .101 \\
\hline $\mathrm{Vx} 1 \mathrm{~L}(\mathrm{~m} / \mathrm{sec})$ & 3.41 & \pm & 0.49 & 8.06 & \pm & 0.70 & 1.677 & .104 \\
\hline $\operatorname{VxMAX}(\mathrm{m} / \mathrm{sec})$ & 8.96 & \pm & 0.61 & 8.49 & \pm & 0.79 & 1.883 & .070 \\
\hline
\end{tabular}

At the examined part of the jump, F12 and F13 athletes were not significantly different $(p>.05)$ concerning the alterations of $\mathrm{H}_{\mathrm{BCM}}$ at the instances examined (Figure 1). An average $\mathrm{H}_{\mathrm{BCM}}$ lowering of $0.05 \mathrm{~m} \pm 0.02$ was recorded during the flight phase of $2 \mathrm{~L}$. In general, the knee angular kinematics were not different between groups. However, a detailed look at the support phase of $1 \mathrm{~L}$ revealed a significant difference $\left(t_{1,29}\right.$ $=2.577, p<.05$ ) concerning $\theta \mathrm{K}_{\mathrm{MF}}(116.8 \mathrm{deg} \pm 9.0$ and $125.4 \mathrm{deg} \pm 9.1$ for $\mathrm{F} 12$ and $\mathrm{F} 13$, respectively) but not for $\theta \mathrm{k}_{\mathrm{TD}}$ or $\theta \mathrm{k}_{\text {TO }}$ (Figure 2). $\mathrm{V}_{\mathrm{A}} \mathrm{TD}$ was not different between groups and it progressively increased during the last two landings of the foot and the final touchdown for the take-off.

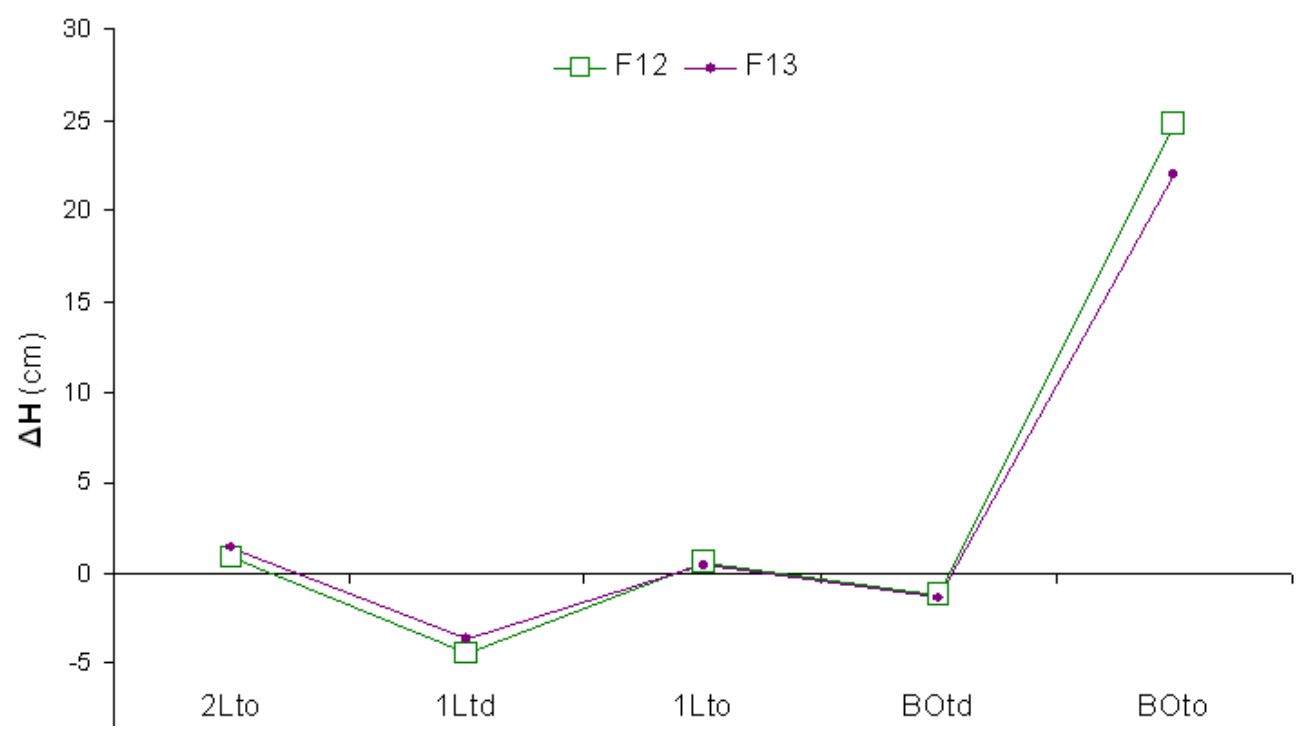

Figure 1. Height alteration ( $\Delta H$ ) of the Body Center of Mass between touchdowns (td) and take-offs (to) for the penultimate stride (2L), last stride (1L) and contact on the take-off board (BO). The lines linking the data points are not intended to represent the actual BCM trajectory 


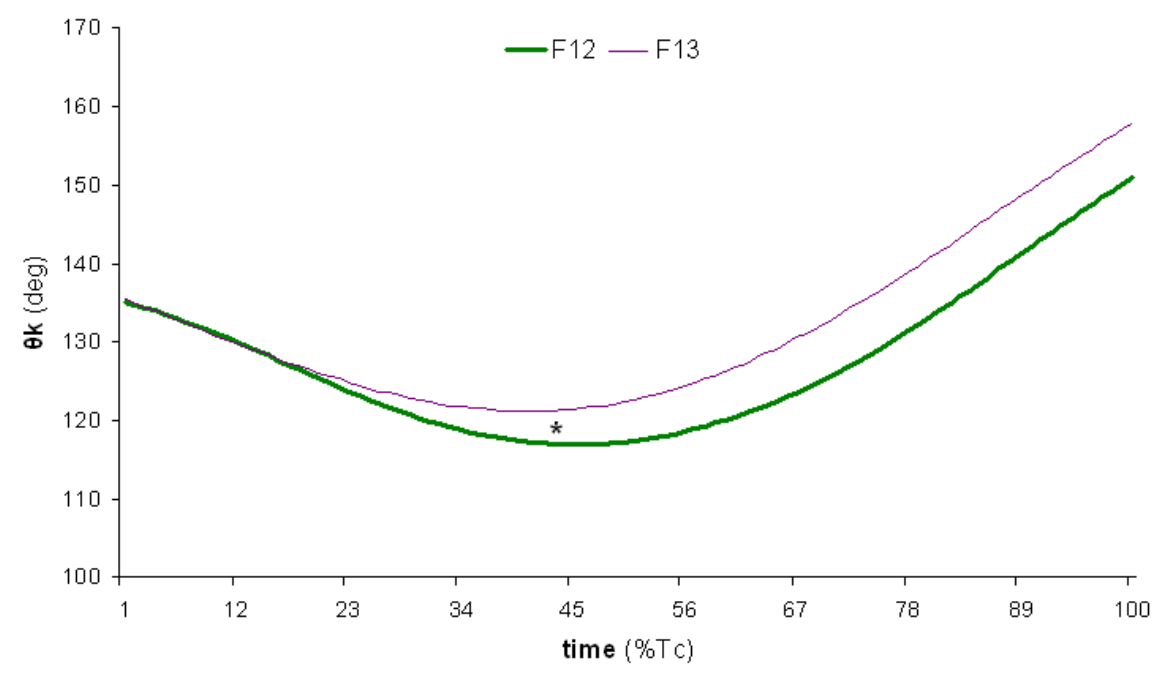

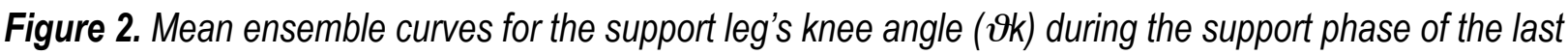
stride. Time is normalized for the comparison. The asterisk indicated statistical significant difference ( $p<$ .05) for the joint angle at its maximum flexion

Table 2 presents the parameters of the take-off phase. F12 had an almost three fold STtB. With the exception of $\mathrm{VyTO}, \theta \mathrm{k}_{\mathrm{FLEX}}$, and $\omega \mathrm{k}_{\mathrm{FLEX}}$, no statistical significant differences were noted.

Table 2. Comparison of the biomechanical parameters of the take-off phase between the examined class F12 and F13 long jumpers (see text for the abbreviations used).

\begin{tabular}{|c|c|c|c|c|c|c|c|c|}
\hline parameter & F12 & & & F13 & & & $t$ & $p$ \\
\hline $\mathrm{S}_{\text {ттв }}(\mathrm{m})$ & 0.28 & \pm & 0.19 & 0.10 & \pm & 0.09 & 3.665 & $.001^{* *}$ \\
\hline $\mathrm{S}_{T D}(\mathrm{~m})$ & -0.60 & \pm & 0.1 & -0.62 & \pm & 0.06 & 0.908 & .371 \\
\hline $\mathrm{U}_{\mathrm{A}} \mathrm{TD}(\mathrm{m} / \mathrm{sec})$ & 2.68 & \pm & 0.59 & 2.68 & \pm & 0.95 & 0.011 & .991 \\
\hline VxTD (m/sec) & 8.20 & \pm & 0.51 & 7.85 & \pm & 0.71 & 1.604 & .120 \\
\hline VxTO (m/sec) & 6.90 & \pm & 0.53 & 6.54 & \pm & 0.68 & 1.649 & .110 \\
\hline$\triangle \mathrm{VxBO}(\mathrm{m} / \mathrm{sec})$ & -1.30 & \pm & 0.46 & -1.31 & \pm & 0.44 & 0.031 & .976 \\
\hline $\operatorname{VyTD}(\mathrm{m} / \mathrm{sec})$ & -0.05 & \pm & 0.23 & -0.20 & \pm & 0.26 & 1.734 & .094 \\
\hline VyTO (m/sec) & 2.81 & \pm & 0.42 & 2.41 & \pm & 0.46 & 2.532 & $.017^{*}$ \\
\hline$\Delta \mathrm{VyBO}(\mathrm{m} / \mathrm{sec})$ & 2.86 & \pm & 0.42 & 2.61 & \pm & 0.46 & 1.568 & .128 \\
\hline $\mathrm{S}_{\text {Tо }}(\mathrm{m})$ & 0.35 & \pm & 0.06 & 0.35 & \pm & 0.06 & 0.227 & .822 \\
\hline $\operatorname{AngPr}\left({ }^{\circ}\right)$ & 21.7 & \pm & 2.8 & 19.9 & \pm & 3.4 & 1.584 & .124 \\
\hline ७kTD (deg) & 158.5 & \pm & 5.5 & 162.5 & \pm & 7.5 & 1.733 & .094 \\
\hline$\vartheta \mathrm{K}_{\text {FLEX }}$ (deg) & -18.2 & \pm & 5.4 & -25.2 & \pm & 5.9 & 3.373 & $.002^{* *}$ \\
\hline$\vartheta \mathrm{k}_{\text {то }}$ (deg) & 173.2 & \pm & 3.6 & 170.8 & \pm & 7.5 & 1.056 & .308 \\
\hline Фтн (deg) & -2.4 & \pm & 7.7 & -2.4 & \pm & 8.5 & 0.812 & .423 \\
\hline بTRSTD (deg) & 93.1 & \pm & 5.6 & 93.5 & \pm & 4.7 & 0.205 & .839 \\
\hline بTRSTO (deg) & 90.5 & \pm & 7.3 & 92.7 & \pm & 6.5 & 0.851 & .402 \\
\hline$\omega \mathrm{k}_{\mathrm{FLEX}}(\mathrm{rad} / \mathrm{sec})$ & -7.4 & \pm & 1.6 & -10.2 & \pm & 3.6 & 2.984 & $.006^{* *}$ \\
\hline$\omega \mathrm{K}_{\text {EXT }}(\mathrm{rad} / \mathrm{sec})$ & 9.9 & \pm & 1.7 & 9.7 & \pm & 1.3 & 0.362 & .720 \\
\hline$W_{B R}(\mathrm{~J} / \mathrm{kg})$ & -6.2 & \pm & 3 & -5.8 & \pm & 3.1 & 0.731 & .688 \\
\hline$W_{P R}(\mathrm{~J} / \mathrm{kg})$ & 2.3 & \pm & 4.2 & 1.1 & \pm & 3.2 & 0.547 & .352 \\
\hline
\end{tabular}




\section{DISCUSSION}

The uniqueness of the present study was that the biomechanical parameters of the last strides and the take-off were examined for visually impaired long jumpers during competition thus supplementing the indelicacy of findings concerning this issue in the respective literature. Results indicated that visually impaired long jumpers were found to execute the final strides of the approach utilizing the "larger penultimate - shorter last stride" technique. However, despite the fact of their lesser visual acuity, class F12 athletes achieved an approximately 10\% longer Soff than class F13 jumpers.

Soff was considerable shorter even than compared to sub-elite European performers in long jump (Panoutsakopoulos \& Kollias, 2007; Panoutsakopoulos et al., 2010). Nevertheless, the difference between class F12 and F13 was in agreement with the trend referring to the respective European IBSA long jump records. With horizontal velocity attained at the last stages of the approach being the single most important determining factor concerning long jump performance (Bridgett \& Linthorne, 2006; Bruggemann \& Conrad, 1986; Fukashiro, 1989; Hay, 1986; Hay, 1993; Hay \& Miller, 1985; Hay \& Nohara, 1990; Hay et al., 1986; Koyama et al., 2011; Panoutsakopoulos et al., 2010), it seams reasonable that F12 jumped further since they were faster than F13 at the final three strides. Additionally, $\mathrm{V}_{\mathrm{A}} \mathrm{TD}$ was not different between groups and it progressively increased during the last touchdowns as noted previously (Koh and Hay, 1990), interpreting a similarity concerning the muscle actions for the preparation of take-off.

During the final stages of their approach, the examined athletes used the "larger penultimate - shorter last stride" technique, a technique that is similarly adopted in visually impaired and sighted long jumpers despite the level of visual acuity (Theodorou et al., 2012b). This finding could be attributed to the fact that the examined jumpers were experienced since they were systematically trained. This long term systematic training has been suggested to allow visually impaired athletes to become independent of visual inputs and to achieve a technique efficiency comparable to sighted athletes (Giagazoglou et al., 2011).

The execution of the "larger penultimate - shorter last stride" technique is widely common in long jumpers as an effective manner to lower $\mathrm{H}_{\mathrm{BCM}}$ prior to the take-off phase (Barros et al., 2007; Bruggemann \& Conrad, 1986; Hay \& Miller, 1985; Hay \& Nohara, 1990; Hay et al., 1986; Kim et al., 2011; Koyama et al., 2008; Mendoza \& Nixdorf, 2011; Muller \& Bruggemann, 1997; Nixdorf \& Bruggemann, 1988; Nixdorf \& Bruggemann, 1990; Panoutsakopoulos \& Kollias, 2009; Panoutsakopoulos et al., 2009; Seo et al., 2011; Shimizu et al., 2011). The greater amount of $\mathrm{H}_{\mathrm{BCM}}$ lowering in both the examined groups occurred during the flight phase of the penultimate stride. This finding is in agreement with previous findings despite the fact that this BCM lowering was smaller in magnitude than those reported in other studies (Koyama et al., 2008; Panoutsakopoulos et al., 2010; Seo at al., 2011). Although not significantly different, both groups had a slightly negative $V y$ at touchdown for take-off, which is suggested to be beneficial for the jump (Campos et al., 2008; Hay \& Nohara 1990; Hay et al., 1986). The combination of low $\mathrm{H}_{\mathrm{BCM}}$ and fast Vx of the approach aids for placing the take-off foot well ahead of the body and for the avoidance of its extensive flexion, factors suggested to contribute in developing a large Vy during the take-off phase (Koh \& Hay, 1990; Lees et al., 1993; Lees et al., 1994). An extended knee at the touchdown on the board is thought to be supplemental to the above factors (Campos et al., 2008; Muraki et al., 2005). Since the maximum Vx of the approach was marginally non-significant different and almost equal values between groups concerning $S_{T D}$, $V_{A} T D, H_{T D}$, and $\theta k_{T D}$ at the board, the longer SofF of class F12 jumpers could be attributed to their larger take-off $V y$ developed as a result of the significantly smaller $\theta k_{F L E x}$. Parameters such as $V y$ comprise the vertical component of the long jumping take-off, with its optimal changes from touchdown to take-off suggested to be a discriminating factor for maximum jumping range (Panoutsakopoulos et al., 2007). It is 
believed that the vertical component is essential for marking better results, especially in female competitors (Lees et al., 1992; Letzelter, 2011).

$\omega \mathrm{K}_{\text {EXT }}$ and $\omega \mathrm{K}_{\mathrm{FLEX}}$ recorded at the take-off phase were within range of previous findings (Muraki et al., 2008). Nevertheless, class F13 jumpers flexed their take-off leg's knee angle with a significantly larger angular velocity that resulted in the significantly smaller $\theta \mathrm{k}_{\mathrm{FLEX}}$ compared to F12 jumpers. This might indicate the inability of the examined F13 athletes to apply enough resistance in order to prevent the excessive knee flexion, since it is believed that an enlarged $\theta \mathrm{k}_{\mathrm{FLEX}}$ is related with weaker lower limb muscles and reduced leg spring force (Lees et al., 1993; Muraki et al., 2005). This is of importance since lower leg stiffness has found to be important concerning the achievement of Soff (Kyrolainen et al., 1988). However, the mechanical work found in the present study was within reasonable agreement with studies concerning sighted athletes (Lees et al., 1993; Lees et al., 1994). It is interesting that vertical jumping performance was shown to be unaffected from the level of visual acuity in both trained and untrained visually impaired individuals (Colak et al., 2004) and that it is not different between visually impaired and sighted persons (Hakkinen et al., 2006; Singh \& Singh, 1993). Based on the above, the force and power production capabilities of visually impaired long jumpers consists an issue that should be further examined.

The causes for the differences occurred during the take-off phase should be checked in the execution of the last stride. Class F12 jumpers had significantly greater $S_{T D}$ and $\theta \mathrm{k}_{\mathrm{MF}}$ than $\mathrm{F} 13$. The latter is proposed to be an indicator of a "vertical" type long jumper that relies on the importance of AngPr in his performance (Shimizu et al., 2012). Results could not establish such a connection, because although F12 had larger AngPr than $\mathrm{F} 13$, the groups were not different regarding the other indicator of "vertical" jumpers ( $\theta \mathrm{k}_{\mathrm{TD}}$ at the take-off board). A further insight in this matter is needed in order to establish a relationship between the parameters of the last stride and the take-off parameters in visually impaired athletes.

Finally, a significant difference was detected between groups regarding the accuracy of the approach, since F12 had an almost three fold Sттв compared to F13, who had a similar STтB compared to non-visual impaired athletes (Kim et al., 2011; Muller \& Bruggemann, 1997; Nixdorf \& Bruggemann, 1990; Panoutsakopoulos et al., 2010). This finding could not establish a visual acuity level effect in long jumping performance, since the rules of the event detect that the measurement of SoFf in class F12 starts at the

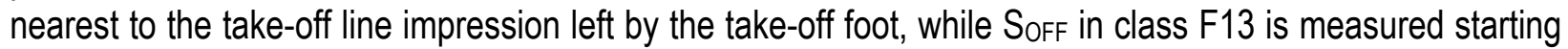

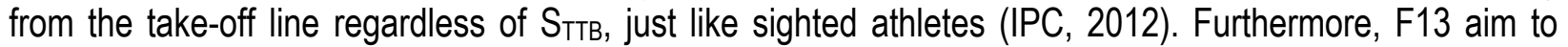
take-off from a regular $0.20 \mathrm{~m} \times 1.22 \mathrm{~m}$ board, while F12 do the same from a rectangle $1.00 \mathrm{~m} \times 1.22 \mathrm{~m}$ chalked take-off area on the approach lane. Even in this case, the sum of STтB and SofF is still significantly smaller in class F13 jumpers. Accurate foot-placement on the board consist a larger constrain than doing so at the wider chalked take-off area. The absence of the take-off aboard or the execution of run-throughs has shows to results in differences concerning the approach parameters (Bradshaw and Aisbet, 2006; Maraj, 1999). Additionally, the average Sттв of $0.10 \mathrm{~m}$ implies that part of the take-off foot was contacting the rubber surface of the approach lane and the rest of the foot was contacting the wooden take-off board. Somatosensory inputs are used for corrective postural actions (Nashner, 1982) and the surface on which visually impaired athletes place their take-off leg might impose a factor that should be accounted for long jumping performance. Under this perspective, the contribution of the width, the surface properties and the color of the take-off area is questionable for the differences concerning the examined groups.

The limited number of participants and the uneven distribution of males and females in class F12 and F13 long jumpers at the analyzed event did not allow the comparison between the two groups without excluding the possible existence of a gender effect. Previous studies reported that a gender effects exist concerning 
variables interpreting physical conditioning abilities (i.e. $V x, V y$ ) and not for the parameters that represent the technical characteristics (i.e. $\theta \mathrm{k}_{\mathrm{MF}}, \mathrm{H}_{\mathrm{BCM}}$ ) of long jumping (Panoutsakopoulos \& Kollias, 2009). Despite this fact, an inter-group preliminary descriptive analysis of the data revealed that the trends of females and males was consistent with the differences observed between class F12 and F13 athletes as an entity, thus considering the results of the comparison of the two examined groups as valid.

It would have seen reasonable that visually impaired athletes would have executed the long jump technique differently than sighted athletes because of their limited visual acuity and thus their supposed inability to regulate their final strides of the approach in order to optimize their take-off parameters. The present study provides evidence that the biomechanics of technique adopted by visually impaired long jumpers was proportionately similar to the one exhibited by sighted athletes. Thus, useful information that is needed for implementing adequate training stimuli is available from the present study for coaches and practitioners concerning the biomechanics of the final stage of the approach of visually impaired long jumpers.

\section{CONCLUSIONS}

The biomechanical analysis of the last strides of the approach for visually impaired long jumpers provide information of the technique elements utilized and the differences caused by the different level of visual acuity. A similar pattern concerning the execution of the final two strides of the approach was revealed between class F12 and F13 athletes. However, class F12 were differentiated concerning the support leg's motion during the last support and the vertical component parameters in the take-off phase. It seems that the width, the surface properties and the color of the take-off area might be supportive for the differences concerning the examined groups. Furthermore, the force application capabilities of visually impaired long jumpers during the impulse for the take-off consists an issue that should be further examined.

\section{REFERENCES}

1. BARROS MLR, MERCADANTE LA, LARA JP, SAKALAUSKAS CB, PRUDENCIO M, CUNHA SA, RUSSOMANO TG, MISUTA MS. A 3D kinematical analysis of long jump in the "Gold Meeting Rio of Athletics 2007". In: H.-J. Menzel, \& M.H. Chagas (editors), In Proceedings of the 25th International Congress in Sports Biomechanics (pp. 487-490). Ouro Preto, Brazil: ISBS. 2007

2. BERG WP, GREER NL. A kinematic profile of the approach run of novice long jumpers. J Appl Biomech. 1995; 11(2): 142-162.

3. BERG WP, WADE MG, GREER NL. Direction of gaze in real-world bipedal locomotion. J Hum Movement Stud. 1993; 24(2): 49-70.

4. BRADSHAW EJ, AISBETT B. Visual guidance during competition performance and run-through training in long jumping. Sports Biomech. 2006; 5(1): 1-14.

5. BRIDGETT LA, LINTHORNE NP. Changes in long jump take-off technique with increasing run-up speed. J Sports Sci. 2006; 24(8): 889-897.

6. BRUGGEMANN GP, CONRAD T. Long jump. In: P. Susanka, G.-P. Bruggemann, E. Tsarouhas (editors), Biomechanical Research in Athletics-1st World Junior Championships, Athens 1986 (pp. 89-119). Athens: SEGAS \& EKAE. 1986.

7. CAMPOS J, GAMEZ J, ENCARNACION E. Kinematical analysis of the men's long jump at the 2008 IAAF's World Indoor Championships in Athletics. In: A. Hokelmann, W. Kerstin, \& P. O'Donoghue (editors), Current trends in Performance Analysis (pp.185-188). Aachen: Shaker Verlag. 2009 
8. COLAK T, BAMAC B, AYDIN M, MERIÇ B, OZBEK A. Physical fitness levels of blind and visually impaired goalball team players. Isokinet Exerc Sci. 2004; 12(4): 247-252.

9. DEMPSTER WT. Space requirements of the seated operator. WADC-TR (55-159). Ohio: Wright Patterson Air Force Base. 1955.

10. FUKASHIRO S. Evaluation of the efficient motion in the running long jump. In: L. Tsarouchas, J. Terauds, B. A. Gowitzke, \& L. E. Holt (editors), Biomechanics in Sports V (pp. 104-111). Athens: HSRI. 1989.

11. GALLOWAY M, CONNOR K. The effect of steering on stride pattern and velocity in long jump. In: R.H. Sanders, \& B.J. Gibson (editors), Scientific Proceedings of the XVII International Symposium on Biomechanics in Sports (pp. 41-44). Perth: Edith Cowan University. 1999.

12. GIAGAZOGLOU $P$, KATIS A, KELLIS E, NATSIKAS C. Differences in soccer kick kinematics between blind players and controls. Adapt Phys Act Q. 2011; 28(3): 251-266.

13. GLIZE D, LAURENT M. Controlling locomotion during the acceleration phase in sprinting and long jumping. J Sports Sci. 1997; 15(2): 181-189.

14. HAKKINEN A, HOLOPAINEN E, KAUTIAINEN H, SILLANPAA E, HAKKINEN K. Neuromuscular function and balance of prepubertal and pubertal blind and sighted boys. Acta Paediatr. 2006; 95(10): 1277-1283.

15. HAY JG. The biomechanics of the long jump. Exer Sport Sci Rev. 1986; 14(1): 401-446.

16. HAY JG. Approach strategies in the long jump. Int J Sport Biomech. 1988; 4(2): 114-129.

17. HAY JG. Citius, altius, longius (faster, higher, longer): The biomechanics of jumping for distance. $J$ Biomech. 1993; 26(Suppl. 1): 7-21.

18. HAY JG, KOH TJ. Evaluating the approach in horizontal jumps. Int J Sport Biomech. 1988; 4(4): 372-392.

19. HAY JG, MILLER JA. Techniques used in the transition from approach to takeoff in the long jump. Int J Sport Biomech. 1985; 1(2): 174-184.

20. HAY JG, NOHARA H. Techniques used by elite long jumpers in preparation for takeoff. J Biomech. 1990; 23(2): 229-239

21. HAY JG, MILLER JA, CANTERNA RW. The techniques of elite male long jumpers. J Biomech. 1986; 19(10): 855-866.

22. KIM HM, WOO SY, KIM YM, NAM KJ, PARK YH, SEO JS. Kinematic analysis of women's long jump at IAAF World Championships, Daegu 2011. Korean J Sport Biomech. 2011; 21(5): 603:610.

23. KOH TJ, HAY JG. Landing leg motion and performance in the horizontal jumps. 1: The long jump. Int J Sport Biomech. 1990; 6(4): 343-360.

24. KOYAMA H, MURAKI Y, AE M. Target value for the maximum run-up speed of the long jump based on the performance level. Port J Sport Sci. 2011; 11(Suppl. 2): 299-302.

25. KOYAMA H, MURAKI Y, TAKAMOTO M, AE M. Kinematics of takeoff motion of the world elite long jumpers. In: Y.-H. Kwon, J. Shim, J.K. Shim, \& I.-S. Shin (editors), Proceedings of the 26th International Congress in Sports Biomechanics (p. 695). Seoul: ISBS. 2008.

26. KYROLAINEN H, AVELA J, KOMI PV. Regulation of muscle force and stiffness during long jump take off. J Biomech. 1990; 22(10): 1042.

27. KYROLAINEN H, AVELA J, KOMI PV, GOLLHOFER A. Function of the neuromuscular system during the last two steps in the long jump. In: G De Groot AP. Hollander PA. Huijing, GJ. Van Ingen Scenau (editors), Biomechanics XI-B (pp. 557-560). Amsterdam: Free University Press. 1988.

28. LEE DN, LISHMAN JR, THOMSON JA. Regulation of gait in long jumping. J Exp Psychol [Human Percept]. 1982; 8(3): 448-459.

29. LEES A, DERBY D, FOWLER N. Sex differences in the jump touchdown and take-off characteristics of the long jump. J Sports Sci. 1992; 10(6): 588-589. 
30. LEES A, FOWLER N, DERBY D. A biomechanical analysis of the last stride, touch-down and takeoff characteristics of the women's long jump. J Sports Sci. 1993; 11: 303-314.

31. LEES A, GRAHAM-SMITH P, FOWLER N. A biomechanical analysis of the last stride, touch-down and take-off characteristics of the men's long jump. J Appl Biomech. 1994; 10(1): 61-78.

32. LETZELTER S. The importance of horizontal and vertical take-off velocity for elite female long jumpers. New Stud Athl. 2011; 26(3/4): 73-84.

33. MARAJ B. Evidence for programmed and visually controlled phases of the triple jump approach run. New Stud Athl. 1999; 14(3): 51-56.

34. MENDOZA L, NIXDORF E. Biomechanical analysis of the horizontal jumping events at the 2009 IAAF World Championships in Athletics. New Stud Athl. 2011; 26(3-4): 25-60.

35. MONTAGNE G, CORNUS S, GLIZE D, QUAINE F, LAURENT M. A perception-action coupling type of control in long jumping. J Motor Behav. 2000; 32(1): 37-43.

36. MULLER H, BRUGGEMANN G-P. Long jump. New Stud Athl. 1997; 13(2-3): 56-59.

37. MURAKI Y, AE M, YOKOZAWA T, KOYAMA H. Mechanical properties of the take-off leg as a support mechanism in the long jump. Sports Biomech. 2005; 4(1): 1-16.

38. MURAKI Y, AE M, KOYAMA H, YOKOZAWA T. Joint torque and power of the takeoff leg in the long jump. Int J Sport Health Sci. 2008; 6: 21-32.

39. NASHNER LM. Adaptation of human movement to altered environments. Trends Neurosci. 1982; 5: 358-361.

40. NIXDORF E, BRUGGEMANN GP. Biomechanical analysis of the long jump. In: Scientific Report on the Second IAAF World Championships in Athletics, 2nd edition (pp. E1 - E54). Monaco: International Athletic Foundation. 1988.

41. NIXDORF E, BRUGGEMANN GP. Biomechanical analysis of the long jump. In: G-P. Brüggemann, \& B. Glad (editors), Scientific Research Project at the Games of the XXIVth Olympiad, Seoul 1988 (pp. 263-302). London: IAAF. 1990.

42. PANOUTSAKOPOULOS $V$, KOLLIAS IA. Biomechanical analysis of sub-elite performers in the women's long jump. New Stud Athl. 2007; 22(4): 19-28.

43. PANOUTSAKOPOULOS $V$, KOLLIAS IA. Biomechanical analysis of the last strides, the touchdown and the takeoff of top Greek male and female long jumpers. Hellenic J Phys Educ Sport Sci. 2009; 29(2): 200-218.

44. PANOUTSAKOPOULOS $V$, PAPAIAKOVOU G, KOLLIAS IA. A biomechanical analysis and assessment of the technique elements of the last strides, the touchdown and the takeoff of junior male and female long jumpers. Inquiries Sport Phys Edu. 2009; 7(3): 333-343.

45. PANOUTSAKOPOULOS V, PAPAIAKOVOU GI, KATSIKAS FS, KOLLIAS IA. 3D biomechanical analysis of the preparation of the long jump take-off. New Stud Athl. 2010; 25(1): 55-68.

46. PANOUTSAKOPOULOS V, TAMPAKIS K, PAPAIAKOVOU G, KOLLIAS IA. Factor analysis of biomechanical parameters which define performance in the long jump. Sport Soc. 2007; 46: 121124.

47. RIDKA-DRDACKA E. A mechanical model of the long jump and its application to a technique of preparatory and takeoff phases. Int J Sport Biomech. 1986; 2(4): 289-300.

48. SCOTT MA, LI F, DAVIDS K. Expertise and the regulation of gait in the approach phase of the long jump. J Sports Sci. 1997; 15(6): 597-605.

49. SEO JS, WOOSY, KIM YW, NAM YH, KIM HM. Kinematic analysis of the men's long jump in the IAAF World Championships, Daegu 2011. Korean J Sport Biomech. 2011; 21(5): 595-602.

50. SINGH R, SINGH HJ. Anthropometric and physiological profiles of active blind Malaysian males. $J$ Sports Med Phys Fitness. 1993; 33(1-4): 378-382. 
51. SHIMIZU Y, AE M, KOYAMA H. A biomechanical study of the takeoff preparation and the takeoff motions in elite male long jumpers. Port J Sport Sci. 2011; 11(Suppl. 2): 381-383.

52. SHIMIZU Y, AE M, KOYAMA H. Biomechanical characteristics of the takeoff preparation and takeoff motions in different jumping types of elite male long jumpers. In: E.J. Bradshaw, A. Burnett, \& P.A. Hume (editors), Proceedings of the 30th International Congress in Sports Biomechanics (pp. 49-53). Melbourne: ISBS. 2012.

53. THEODOROU A, SKORDILIS E. Evaluating the approach run of class F11 visually impaired athletes in triple and long jumps. Percept Mot Skills. 2012; 114(2): 595-609.

54. THEODOROU A, SKORDILIS E, TASOULAS E, SMIRNIOTOU A, PARADISIS G. Stride regulation at the approach phase of long jump in visually impaired (F13) athletes. Port J Sport Sci. 2011; 11(Suppl. 2): 395-397.

55. THEODOROU A, SKORDILIS E, PLAINIS S, TASOULAS E, PANOUTSAKOPOULOS V, PADULLES-RIU J, TORRALBA-JORDAN M, PANTELI F. Stride length regulation at the approach phase of long jump in visually impaired (F12 class) athletes. In: E.J. Bradshaw, A. Burnett, \& P.A. Hume (editors), Proceedings of the 30th International Congress in Sports Biomechanics (pp. 3336). Melbourne: ISBS. 2012a

56. THEODOROU A, PANOUTSAKOPOULOS V, KOTZAMANIDOU MC, PLAINIS S, SKORDILIS E, PAPAIAKOVOU GI. Adjustments of stride length and accuracy of footfall at the take-off board of sighted and visually impaired female long jumpers. Proceedings of the 5th Congress of the Hellenic Association of Therapeutic Exercise and Special Physical Education (pp. 51-53). Thessaloniki: HATESPE. 2012b

57. WINTER DA. Biomechanics and motor control of human movement, 2nd edition. Toronto: John Willey \& Sons. 1990 